\title{
Coarticulation in non-native speakers of English: /alV/- sequences in non-proficient vs. proficient learners
}

Henrike Baumotte and Grzegorz Dogil

Institute for Natural Language Processing, Universität Stuttgart, Germany

https://doi.org/10.36505/ExLing-2008/02/0010/000069

\begin{abstract}
This is an acoustic study of the production of English /1/ by Standard German speakers. Previous research categorized these speakers as either non-proficient or proficient with regard to their phonetic abilities. Coarticulation differences might be one of several reasons for less proficient speakers not to be able to overcome their foreign accent. The pattern of consonantal velarization influences the degree of /əlV/-coarticulation within the group of L2 speakers. Significant F2 and Fv values for non-proficient vs. proficient speakers suggest that proficiency can be characterized due to English stimuli being articulated with more active tongue dorsum control (more velarization) which does not appear as such in German language.
\end{abstract}

Key words: coarticulation, coarticulatory resistance, foreign accent, acoustic measurements, formant values

\section{Introduction}

In running speech, articulatory gestures overlap in time, leading to interaction between successive phonetic segments, referred to as coarticulation. Previously, several studies investigated coarticulation and found cross-language differences (Öhman 1966; Manuel 1990; Recasens, Fontdevila and Pallarès 1995). Recasens, Fontdevila and Pallarès (1995) reported for German the value for F2 in /1/ to be lower overall than in other languages. The tongue dorsum is more constrained for German non-velarized [1] and thus less sensitive to coarticulatory effects from, e.g., /i/ or /a/. The authors compared German with Catalan production and observed greater dorsal contact at the palatal zone for German [1] than for Catalan [ 1 ]. In line with the surrounding formant frequencies for the vowel /a/, consonantal effects on F2 for /a/ are also large because no defined vocal-tract shape is necessary for the production of $/ \mathrm{a} /$; this is why schwa is highly sensitive to coarticulation (Recasens 1985).

\section{Methods}

Formant frequency data were collected for the sequence /dZəl[a, i, y:, $\mathrm{u}] \mathrm{t} / \mathrm{spoken}$ in as native-like as possible Standard Southern British English, embedded in carrier sentences (I have said [...] twice.) with stress on the

ExLing 2008: Proceedings of 2nd Tutorial and Research Workshop on Experimental Linguistics, 25-27 August 2008, Athens, Greece 
second syllable. This speech material was read five times by each of 21 native German speakers resulting in 420 tokens ( 1 consonant x 4 vowels x 5 repetitions x 21 speakers). Subjects took part in extensive tests of phonetic language ability based on the large scale DFG project "Language Talent and Brain Activity", which assessed pronunciation talent in English before. In the beginning of each session subjects were instructed to repeat a small text presented by a native speaker, to help speakers to switch from one language mode to the other. Digital recordings were made at a $16 \mathrm{kHz}$ sampling rate in a sound-attenuated room in the phonetics laboratory at the Universität Stuttgart. The data were then segmented at the phon level by automatic forced alignment (Aligner, St. Rapp, IMS) and formant frequencies were measured every $10 \mathrm{~ms}$ with the ESPS formant program. $\mathrm{F}_{2}$ and $\mathrm{F}_{1}$ were extracted from the middle of the steady state in $/ \mathrm{a} /$.

\section{Results and discussion}

Based on previous studies we predicted that velarized native-like English [1] should show less coarticulatory effects on /a/ before / $1[\mathrm{a}, \mathrm{i}, \mathrm{y}:, \mathrm{u}] /$ than nonvelarized less proficient articulated English [1] (no active tongue dorsum gesture). $F_{2}$ frequency and the frequency distance between $F_{2}$ and $F_{1}, F_{v}$, which considers also the contribution of $F_{1}$ known to be inversely related to velarization (Recasens, Fontdevila and Pallarès 1995: 41), served as indicators for the degree of consonantal velarization. Following these assumptions $F_{2}$ and $F_{v}$ in less proficient English speakers should be lower than in proficient speakers.

Statistical analysis showed significant $\mathrm{F}_{2}$ and $\mathrm{F}_{\mathrm{v}}$ differences between nonproficient and proficient non-native English speakers; while for proficient speakers mean $\mathrm{F}_{2}$ values (mean value: $1874,70 \mathrm{~Hz}$ ) were higher than for nonproficient speakers (mean value: 1776,68 Hz).

F2

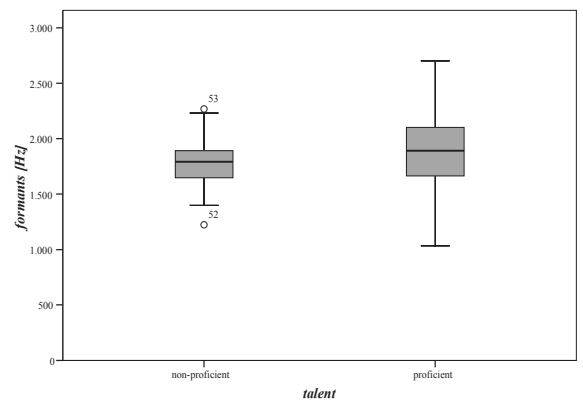

Fv

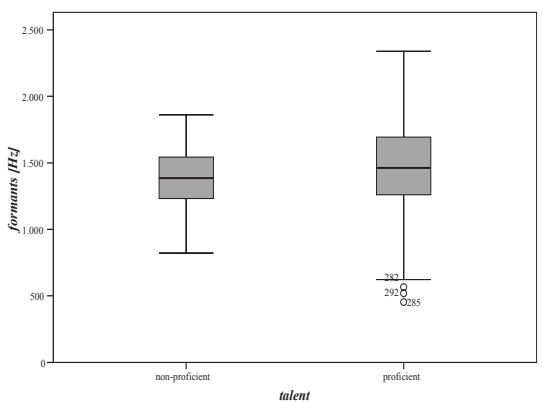

Fig. 1. Distribution of $F_{2}$ (left) as well as $F_{v}$ in non-proficient vs. proficient speakers (right). 
Table 1. $t$-test-results after comparison of $\mathrm{F}_{2}$ as well as $\mathrm{F}_{\mathrm{v}}$ in non-proficient vs. proficient non-native English speech.

\begin{tabular}{|l|l|l|}
\hline comparison & $\mathrm{T}=$ & significance \\
\hline $\mathrm{F}_{2}$ & $-2,354$ & $p=0,019$ \\
\hline $\mathrm{F}_{\mathrm{v}}$ & $-2,084$ & $p=0,037$ \\
\hline
\end{tabular}

In non-proficient speakers $\mathrm{F}_{\mathrm{v}}$ was lower (mean value: 1371,57 Hz) than in proficient speakers (mean value: 1464,83 Hz). Oh (2008) investigated coarticulation differences in native vs. non-native French as well as English speakers and concluded that more experienced learners developed more native-like degrees of coarticulation than less experienced learners did. In accordance to Oh's results, these data suggest that proficient speakers acquire better the fine-grained language-specific patterns of coarticulation. Subjects categorized as less proficient might not automatically be able to enlarge their stored phonetic features after having heard a sound which is not similar to those existing in their mother tongue. As a consequence, during L2 production not as many exemplars as in proficient speakers can be activated (Pierrehumbert 2001). The use of tongue dorsum control, tongue dorsum fronting and raising might correlate with perception abilities. Keating (1990) proposed that language-specific phonetic details of each language, coarticulation and its amount are specified separately in the grammar of each language. Therefore, amount of $/ 1 /$-velarization might not necessarily be exploitable for language learners. In future work, we would like to further unravel whether coarticulation differences in non-proficient vs. proficient speakers occur due to perceptual distinctiveness constraints or to independent learning of coarticulatory patterns.

\section{Acknowledgements}

This work was supported by the German Science Foundation, Graduate School 609, Universität Stuttgart, Germany. We would like to thank PD Dr. Wolfgang Wokurek for support and advice.

\section{References}

Bladon, R.A.W. and Al-Bamerni, A. 1976. Coarticulation resistance in English /1/. Journal of Phonetics, 4: 137-150.

Keating, P.A. 1990. The window model of coarticulation: Articulatory evidence. In: Kingston, J. and Beckman, M. E. (eds): Papers in laboratory phonology I: Between the grammar and physics of speech. Cambridge: Cambridge University Press., pp. 451-470.

Manuel, S.Y. 1990. The role of contrast in limiting vowel-to-vowel coarticulation in different languages. Journal of the Acoustical Society of America, 88: 1286-1298. 
Oh, E. 2008. Coarticulation in non-native speakers of English and French: An acoustic study. Journal of Phonetics, 36: 361-384.

Öhman, S. E. G. 1966. Coarticulation in VCV utterances: Spectrographic measurements. Journal of the Acoustical Society of America, 39: 151-168.

Pierrehumbert, J. 2001. Exemplar dynamics: Word frequency, lenition and contrast. In: Bybee, J. and Hopper, P. (eds): Frequency and the Emergence of Linguistic Structure. Amsterdam: Benjamins, pp. 137-157.

Recasens, D. 1985. Coarticulatory patterns and degree of coarticulatory resistance in Catalan CV sequences. Language and Speech, 28 (2): 97-114.

Recasens, D., Fontdevila, J. and Pallarès, M. D. 1995. Velarization degree and coarticulatory resistance for $/ 1 /$ in Catalan and German. Journal of Phonetics, 23: $37-52$. 